\title{
DIGITAL CAPTURE AND FABRICATION TOOLS FOR INTERPRETATION OF HISTORIC SITES
}

\author{
A. Ackerman ${ }^{\mathrm{a}}$,E. Glekas ${ }^{\mathrm{b}}$
}

aBoston Architectural College, Landscape Architecture Faculty, 320 Newbury Street, Boston, MA 02115 (aidan.ackerman@ the$\underline{\text { bac.edu }}{ }^{b}$ Boston Architectural College, Historic Preservation Faculty, 320 Newbury Street, Boston, MA 02115 (eleni.glekas@ thebac.edu)

\section{Commission II}

KEY WORDS: Digital archiving, heritage documentation, photogrammetry, fabrication, laser cutting, 3D printing, heritage conservation, landscape conservation

\begin{abstract}
:
Historic sites and the narratives they produce can have a lasting impact on the community through public engagement and education. However, when these sites are neglected and lost over time, opportunities to engage the public with the history of these places is lost with them. The interpretation of heritage that has been lost or forgotten is an emerging trend in humanities studies. This trend, in combination with technological advancements in digital media and representation, presents an innovative opportunity for historic preservation professionals to create new paths for public engagement. This paper discusses applications of photogrammetry, 3D modeling, and digital fabrication in digitally reconstructing interpretive models of the Larz Anderson Estate (now Larz Anderson Park). This site has changed dramatically through its transition from a private estate to a public park and recreation area, with few remnants of the original estate remaining extant. The above stated use of digital strategies aims to create digital and physical models of the estate's change over time, with the aim of interpreting the site's lost heritage for the public. Combining existing archival research and heritage documentation methods with these digital representation techniques tells the story of a place that no longer exists.
\end{abstract}

\section{INTRODUCTION}

Starting in fall 2015, the Boston Architectural College (BAC) has been working with the Town of Brookline (the Town) and the Larz Anderson Auto Museum (LAAM) on a variety of different projects relating to the documentation and interpretation of Larz Anderson Park, a 64 acre public park in Brookline, MA and former Gilded Age era estate of Larz Anderson and Isabel Weld Anderson. This project initially began when the BAC was approached by the Larz Anderson Auto Museum to create a scale model of the estate in its entirety in 1927 as a museum exhibit piece and interpretive tool for greater public engagement with the historical roots of the museum and park. This project was significant for the museum, as it would be the first time a comprehensive and historically accurate model of the site had ever been created. In order to create this model, researchers needed to collect and synthesize disparate documentation material, which was scattered around various archives in Massachusetts and Washington DC. This material included site plans, written accounts, photographs and other items. Once these documents were gathered, extensive site analysis work was then conducted through measured drawings, sketches, large format photography, and finally 3D models developed through close range photogrammetry (CRP). This data was then used as a basis for a digital fabrication process that led to the creation of a scale model of the estate as it stood in 1927.

\section{HISTORY OF THE PARK AND BUILDING}

The history of Larz Anderson Park began during the $19^{\text {th }}$ century in Brookline, a wealthy and fashionable suburb of Boston, as the Weld Estate, the family home of Isabel Weld Anderson. Isabel and her husband, Larz, acquired the estate in 1899 , but it had been in Isabel's family for several generations. Her cousin, William Fletcher Weld II, inherited the estate from their grandfather in 1882 and immediately began expanding and improving the site. He acquired fifty adjacent acres and constructing a new shingle style house and carriage house in 1887 (Moskey 2016), designed by notable Boston architect Edmund March Wheelwright (Figure 1), whose other works include the Longfellow Bridge and the Boston Opera House. Upon William's passing in 1893, the estate was eventually transferred to Isabel in 1899 (Moskey 2016). 

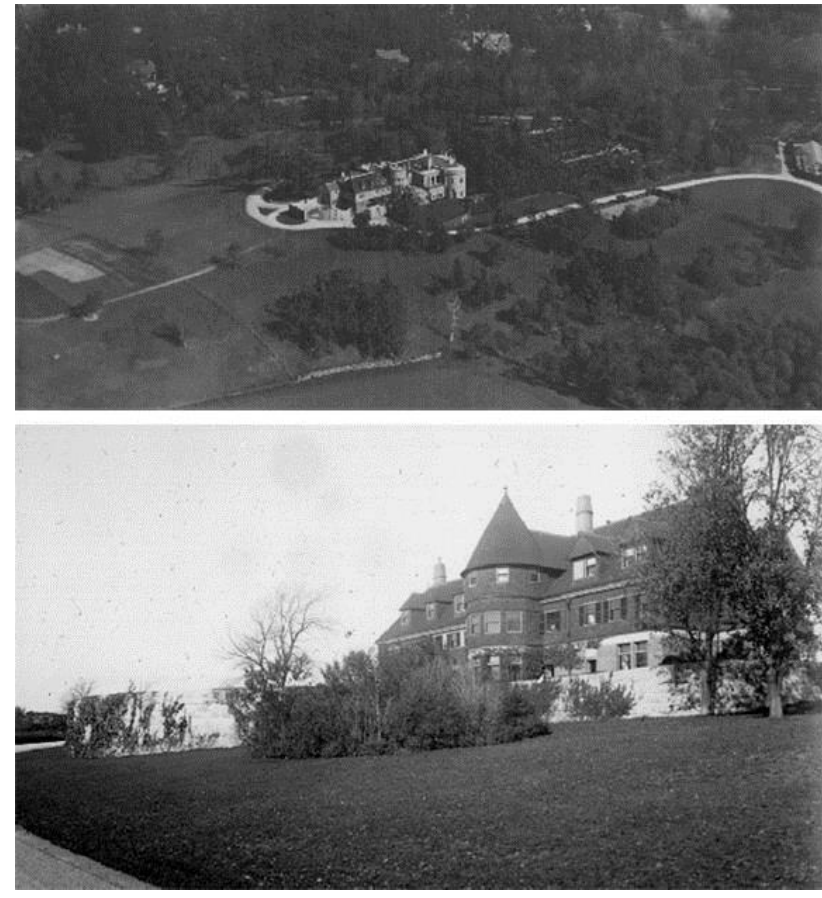

Figure 1. The main house at Weld by E.M. Wheelwright, early 20th century. Source: Historic New England Archives

Isabel married Larz Anderson, a US Diplomat, in 1897. Due to Larz Anderson's diplomatic duties, the Andersons lived and traveled throughout the world and spent much of their time in Washington, D.C. The influences of their travels are reflected in design of their homes and landscaped gardens in their Brookline and Washington, D.C. homes.

While they were in Brookline, the Andersons frequently opened up the grounds of their estate for public use. They were also avid car collectors purchased one new car each year starting in 1899. Larz and Isabel began a Sunday tradition of opening up their garage to the public and show their expanding collection. In addition to the car shows, Isabel would host public showings of plays that she wrote in her outdoor theater, the Four Seasons (Brookline Historical Society, 1989). This would later become the impetus for the creation of the Larz Anderson Auto Museum.

The carriage house, which later became the garage that housed the Anderson's car collection, is one of the only surviving original structures left in the park and is well preserved as the home of the Larz Anderson Auto Museum (Figure 2). Wheelwright modeled it after the Chateau de Chaumont in the Loire Valley region in France.

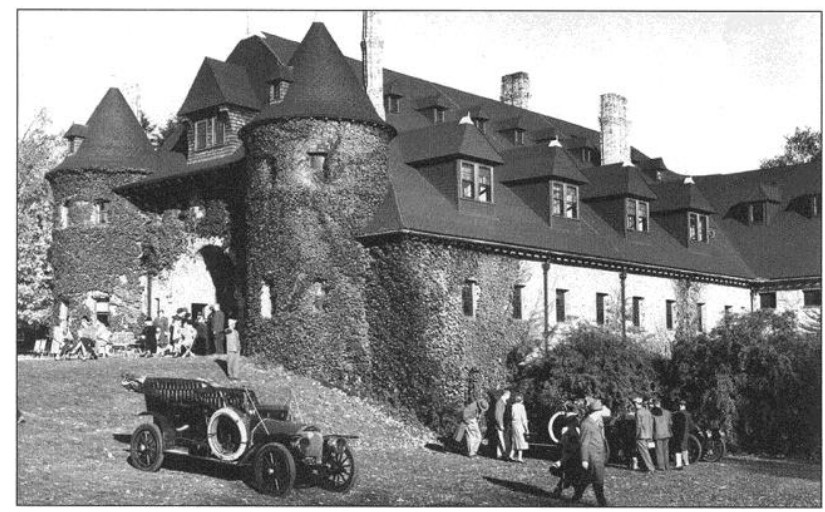

Figure 2. Larz Anderson Auto Museum on opening day in 1953. Source: Evan P. Ide

The most prominent landscape features were designed by renowned landscape architect Charles A. Platt. His major contribution was the Italian Garden (Figure 3), which was considered one of the finest examples of its time and one of the most photographed gardens in the United States (Kenworthy, 1991).

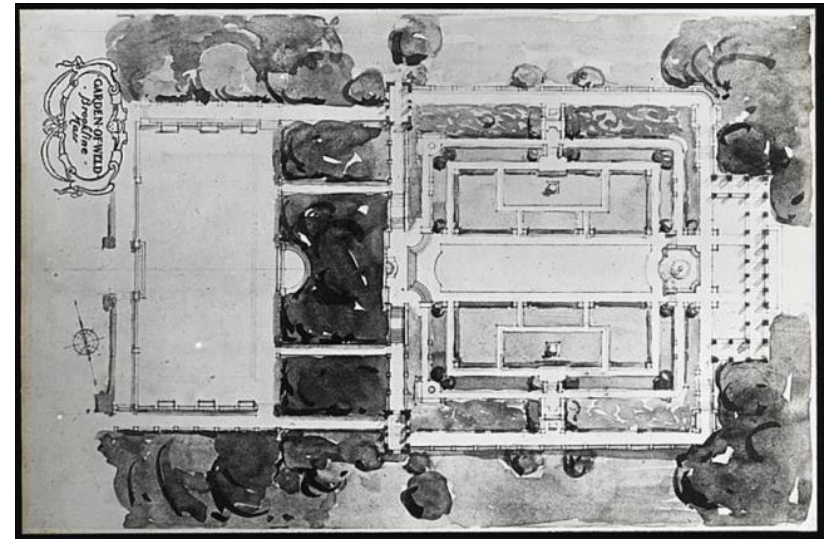

Figure 3. Charles A. Platt plan of Italian garden at Weld, 1915. Source: Library of Congress

Other major landscape features, most notably the English Garden (also called Water Garden or lower garden) and Chinese Garden, were designed by the Boston-based architectural firm Little \& Browne, whose commissions included many other private estates of wealthy New Englanders who were contemporaries of the Andersons. These were some of the last major decorative landscape features to be constructed at Weld.

Upon Isabel's passing in 1948, her entire estate was left to the Town of Brookline. The main house, gardens and much of their car collection was transferred to public use as the Andersons had no heirs. Isabel stipulated in her will that it was "to be used by said Town for the purposes of public recreation, or for charitable purposes, or for the purpose of public education." There were no additional funds allocated to the maintenance and upkeep of the ornate designed landscapes or the mansion. Over time, these elements fell into a state of disrepair and the main house itself was eventually demolished. ${ }^{2}$ The Town did not have the financial means to support the same level of upkeep and had to devise other ways to manage the new property they had been given and they entrusted a board of selectmen to oversee the use and management of the property.

Isabel's bequest to the Town of Brookline also included the carriage house and their extensive car collection, which would become the initial collection for the Larz Anderson Auto Museum. The estate itself suffered a different fate. After several attempts to come up with an appropriate use for the structure, the board of selectmen ultimately decided to demolish the house in the 1950s (Moskey 2016). This was paired with the decision for the Town of Brookline to place an ice skating rink in the

${ }^{1}$ This quote comes from the last will and testament of Isabel Weld Anderson, December 30, 1949.

${ }^{2}$ Much of the anecdotal information comes from oral histories of the Executive Director of the Larz Anderson Auto Museum, which houses the only museum exhibit on the Andersons. These oral accounts were collected through several field visits to Larz Anderson Park and LAAM over the course 2015 and 2016. 
location of the Italian Garden, which became too expensive for the town to maintain.

This also coincided with the changes in the way open space and recreation were viewed in the 1950s and 60s (Platt 1994). As active forms of recreation became more popular in the postwar era, many changes came to Larz Anderson Park. In addition to the replacement of the Italian Garden with an ice skating rink, the polo grounds were replaced with baseball diamonds, the walking paths were paved and the Chinese Garden was replaced by a community garden (Figure 4). Finally, a parking lot was placed at the top of the hill where the main house once stood to accommodate more visitors.

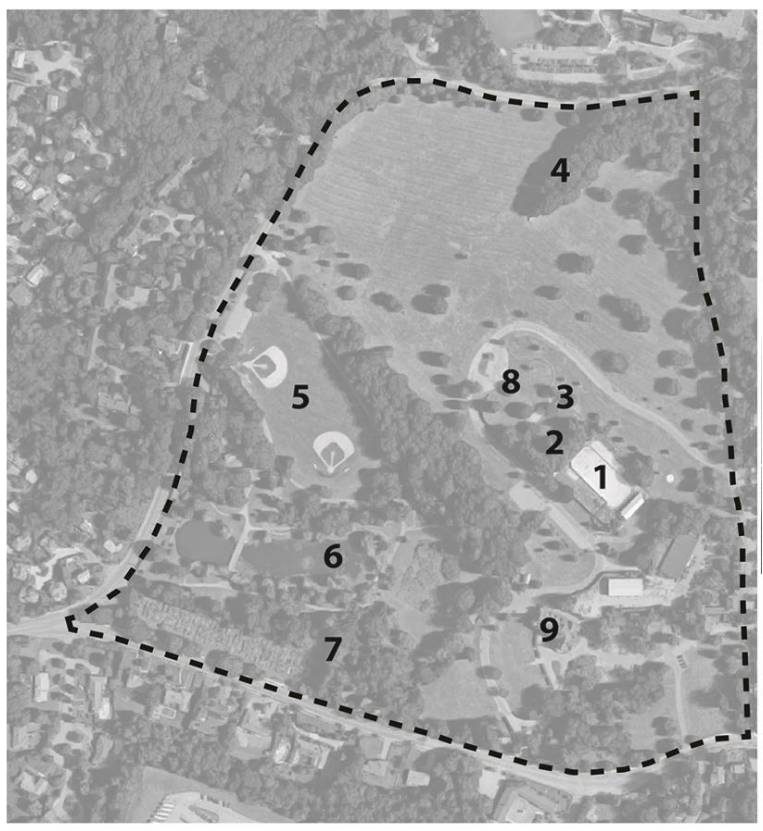

Weld Estate: Landscape Elements

1. Italian Garden (1901, Charles Platt)

2. Grove and Bowling Green (1901, Charles Platt)

3. Japanese Garden (Onchi-San, 1907)

4. Allee with Seats (1903)

5. Polo Fields

6. Water Garden/Tempietto (Little \& Browne, 1910)

7. Chinese Garden (Little \& Browne, 1910)

8. Mansion (E.M. Wheelwright, 1887, demolished circa 1950)

9. Carriage House and Garage (E.M. Wheelwright, 1888)
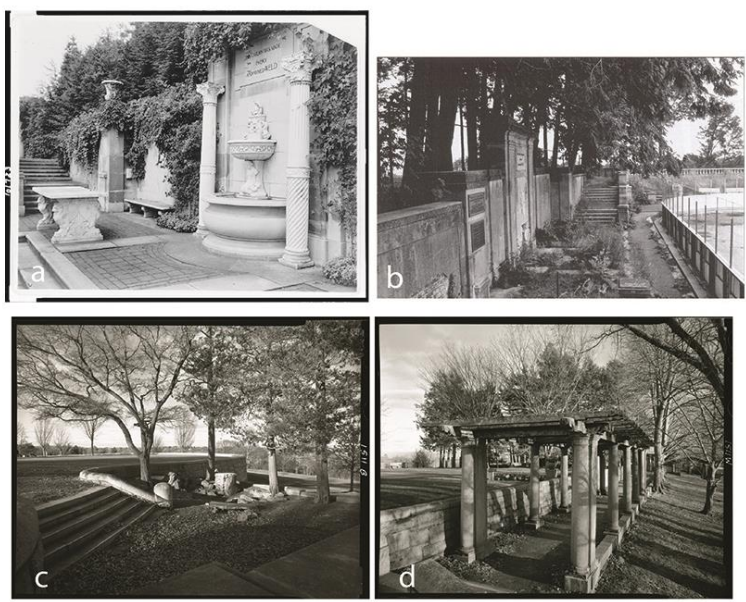

Figure 4. Key landscape features of the Weld Estate (now Larz Anderson Park). (a) Fountain at the Italian garden circa 1925 (b)

Remnants of Italian garden behind ice skating rink in 2004 (c)

Remnants of the Japanese garden in 2016 (d) Bowling green

near footprint of the main house in 2015. Image credits: Google maps, Library of Congress, Evan Ide, Andrew Barr.

Despite the fact that the original estate no longer exists and many of the garden elements are missing, Larz Anderson Park still remains culturally and historically significant for other reasons, most notably its change in use as a reflection of changing nature of public open space during the 20th century in the United States. Upon Isabel's passing and the transfer of the land to the Town of Brookline, Larz Anderson Park changed use from a private estate to a public park. This change in use also changed its significance, going from an architectural and landscape masterpiece to a public amenity for local residents, as noted above. During the Anderson's time, the design philosophy of the Picturesque movement popularized a more romantic notion of open space as an escape from harsh urban life (Schmidt, 2008). At this time Brookline was seen as a distant suburb of Boston, far away from the ills of the city. Today, the city of Boston has caught up with Brookline, and although it is a separate municipality, it is ensconced within the dense urban fabric of the city through various transportation networks and an expansion of the borders of Boston. The notion of parks and open space morphed from a focus on re-creating the English countryside and escaping the harshness of urban life to prioritizing active recreation. Creating space for athletic activities that were more popular with the general public, such as hockey and baseball, became a greater priority for local planning authorities.

\section{THE NEED FOR A DOCUMENTATION PROJECT}

Today the site is regularly used as a public park by local Brookline residents. However, most visitors do not know the history of the site and the prominent role it played in Brookline's early history. Interpretation of the gardens and built features is limited as there is no coordination between the Larz Anderson Auto Museum and the Town of Brookline on educational programming. There is a lengthy PDF of a self guided walking tour available on the LAAM website, but navigating the tour is difficult for visitors and it is poorly advertised. The interpretation of the site is also limited to architectural history and the history of the Andersons. There is no material to educate park visitors on the origins of the site or how it has changed over time, despite the fact that there are remnants of the sites history littered throughout the sixty-four acre landscape. None of the changes to the site were properly documented, leaving many gaps in information. This created the need to improve the archival record and create a comprehensive site model of the estate in its entirety.

Digital tools can help meet this need for improved archival records, and as such have an established usage in recreating heritage buildings and sites. 3D models of historic buildings have gone beyond visual interpretations to begin providing structural information about these structures, leading to crossplatform applications of this information (Boeykens, 2009). These 3D models, often captured through photogrammetry or laser scanning, have an established history of being reproduced through digital fabrication workflows to produce tactile physical models (Martens, 2005). Beyond capturing heritage sites for posterity, digital tools offer effective methods for virtually restoring sites which have been partially or completely lost. This workflow seamlessly integrates newly-modeled geometry with existing site conditions to rapidly explore reconstruction 
techniques (Hamani, 2014). Recreated 3D models can take advantage of augmented reality techniques to be virtually "located" on the site and viewed through a digital device, such as a phone or wearable goggles, allowing visitors to a site to virtually experience lost heritage as it once stood (Chung, 2009).

\section{PROJECT OVERVIEW \& PROCESS}

In order to facilitate the creation of a comprehensive and historically accurate scale model of the estate in a time sensitive way for the LAAM, researchers in the Historic Preservation, Landscape Architecture and Digital Design and Visualization programs at the BAC began to use existing classes in heritage documentation and digital fabrication as a way to begin the site analysis and archival research work. Capitalizing on the aforementioned existing digital documentation techniques the team was able to create new documentation site that never previously existed, thus adding to the historical record of the estate and filling information gaps that were present only in scattered archives.

The first step in creating the scale model of the Weld Estate was to delve into existing documentation pertaining to the site. Much of the archival documentation related to the site was scattered throughout various archives at the Town of Brookline, Library of Congress, Historic New England, Boston University and the archives of the Society of the Cincinnati. Archival material relating to the site came in the form of photographs, Larz and Isabel Anderson's personal journals, legal documents and original drawings. This data was centralized in a digital clearinghouse of archival information through Omeka ${ }^{3}$, an open source digital publishing system. This documentation process was the first step in what would lead to the creation of digital base files for the estate. The Omeka database served as a resource for developing an initial understanding of the site's layout and geometry; 3D modelers referred back to the database throughout the digital file process to investigate specific details or identify the site's developments at certain points in time.

The intent of this effort was not to organize existing archival material for posterity, but rather conduct a comprehensive overview of existing material to identify information gaps for the modeling process. For example, it was well established that the main house had been demolished, but the demolition methods themselves were unclear. Conflicting accounts exist with different dates and varying descriptions of how the main house was ultimately demolished. Identifying these gaps in knowledge became an important process for the creation of the base files for the model, as these gaps informed what details required further research before they could be included in the model.

To create an architectural-scale digital fabrication model for this project, a team of faculty and students combined many existing tools and techniques such as $\mathrm{CAD}$ drawing, 3D modeling, laser cutting, and 3D printing to assemble a final model of the Larz Anderson Estate. Creating the model allowed the team to test archival documents such as building plans, site surveys, and historic photographs for accuracy, consistency, and gaps in information. Local historic archives were researched, and relevant documents were identified such as scale drawings of the estate's buildings and landscape. These documents provided a reliable starting point to develop CAD drawings of the terrain,

\footnotetext{
${ }^{3}$ Omeka (www.omeka.com) describes itself as a web publishing
} platform, using Dublin Core as its metadata standard. vegetation, and architecture (Figure 5).

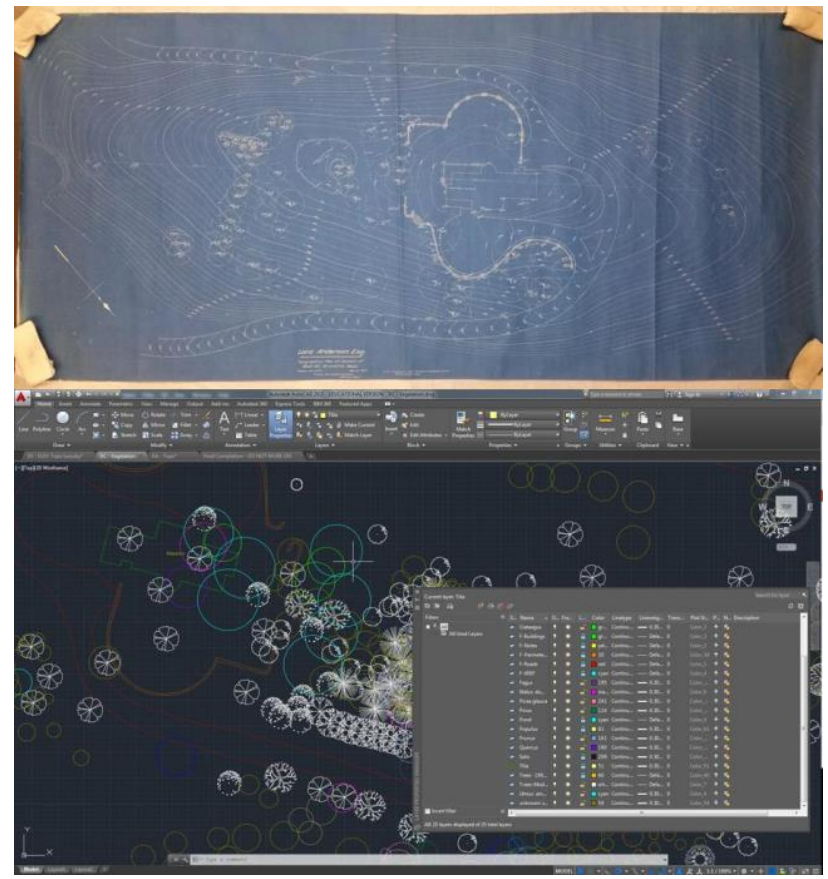

Figure 5. CAD drawing of Anderson site from historic site plans

The 3D modeling process itself involved translation of site topography from old site survey drawings, modeling the estate's buildings using information from drawings and photographs, and locating and modeling significant vegetation. No comprehensive site plan could be found, and so in many cases the students were required to perform deeper research to respond to these missing areas. A key finding of this project is that the demands of creating a physical model necessitated a thorough research approach, allowing few if any gaps in information to persist. An additional finding relates to the unexpected utility of process work: once the digitally-fabricated model was complete, the $\mathrm{CAD}$ and $3 \mathrm{D}$ models used for fabrication were in themselves useful artifacts. These artifacts can be used to create digital renderings, flythrough animations, time-lapse sequences, and other useful tools for digital heritage interpretation.

Determining correct scale was important; measured drawings provided much of the scale measures. Where no dimensions or scaled drawings existed, proportional measures were approximated based off of the buildings or structures that still remained on the site. Where none of these options were available, photographs oven gave clues about dimensions: a specific material, a person in the picture, or a tree species known not to exceed a certain height could all be used to provide clues about the scale of a particular building. This approach has been used by researchers in documenting existing historic sites which do not have measured drawings; in the case of visualizing the historic village of New Lanark, 3D models were built using a combination of measured drawings and proportional scales (Lee, 2000). In one such case, a trellis that was part of the original gardens appeared in a photograph and was indicated on the site plan, but no dimensions existed. Researchers were able to locate a small portion of the trellis which had been moved from the estate to a nearby community garden, which was visited and measured. These measurements were used to construct a 3D model and 3D printed replica of the trellis. This research additionally provided valuable information 
later on in the project, when it became necessary to reconstruct a 3D model of a greenhouse connected to the trellis. No drawings existed of the greenhouse, only photos, but the trellis dimensions provided enough information to reference the proportional scales of the rest of the greenhouse model (Figure $6)$.
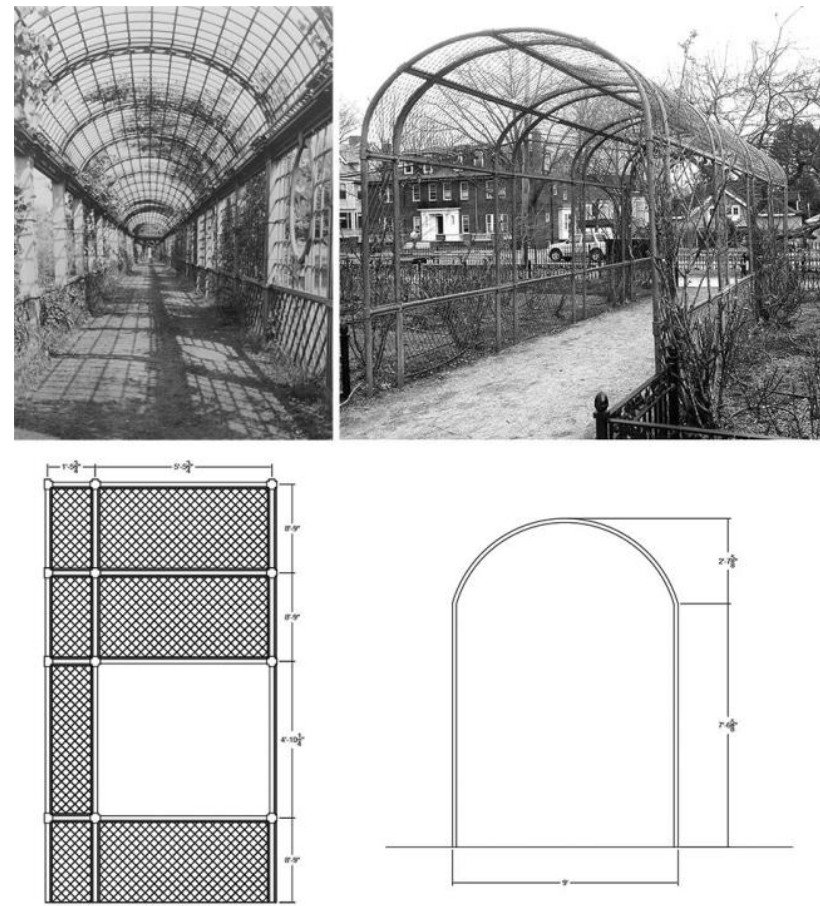

Figure 6. Trellis original and new location, and measurements

Two fabrication techniques were used to create the main components of the model. For the site topography, the CAD contours were used to create laser-cut files. Once the final scale of the model was determined, each CAD contour was then laser-cut out of a piece of chipboard using a VLS 6.60 laser cutter. The model was separated into four quadrants so that the completed model could exceed the dimensions of the laser bed. Each layer was cut out and glued to the layer beneath, with building footprints cut into the model to allow the buildings to nest into the layer of chipboard. The buildings themselves were 3D printed out of plastic using a Zortrax M200 3D printer with ABS filament, with information being taken from archival drawings and photographs.

\section{DISCUSSION}

The process of creating digital files and fabricating a model from these files required extensive research to answer critical questions which were not answered by the existing information about the estate. The final model carried an important burden: it would be viewable from all sides and numerous angles. Visitors needed to be able to stand back and take in the entire model, or get very close and observe a small detail. The level of craftsmanship necessary to support these multiple viewings required care as well as accuracy. Certain models have the luxury of having a front, sides and a back: if a side was not meant to be viewed, it could be left incomplete and facing away from the viewer in such a way that they could not access this side. The Larz Anderson Park model's design was unable to support such privileged viewing, instead needing to provide a full and complete level of finalized detail from all conceivable angles. This presented a significant challenge due to the incomplete nature of the existing archival documentation. In some cases, little or no information was immediately available to provide necessary information on a critical detail. In one such case, it was unclear from the drawings how exactly the Anderson mansion's terrace was constructed to meet a sloped grade with a retaining wall on one side. The option to omit this part of the model, or simplify it somewhat, did not exist in this project - the model's scope demanded this level of detail. It was this demand that in turn energized the researchers to find answers where none were immediately available, looking through additional documents, visiting historic records, reading notes on the project, and searching deeper into archives for photographs which might provide this information. After a lengthy search, new documents were discovered which provided enough detail to understand this terrace detail.

As another example, the researchers encountered some uncertainty regarding a detail of the Larz Anderson mansion. Blueprints show a carriage port at the rear of the mansion, yet the only archived aerial photograph of the mansion does not include a carriage port. The angle of the photograph makes it unclear whether the carriage port was missing or simply obscured by the top story of the mansion. As an important feature of the model, the mansion's detail needed to be completely accurate. This uncertainty prompted the researchers to continue searching for clarifying information which would answer the question of the carriage port's presence. Further research eventually uncovered a photograph taken around the same time but at a different angle, and which clearly showed that no carriage port was present. This led the researchers to conclude that the carriage port was specified in the original drawings of the mansion but was never built. 

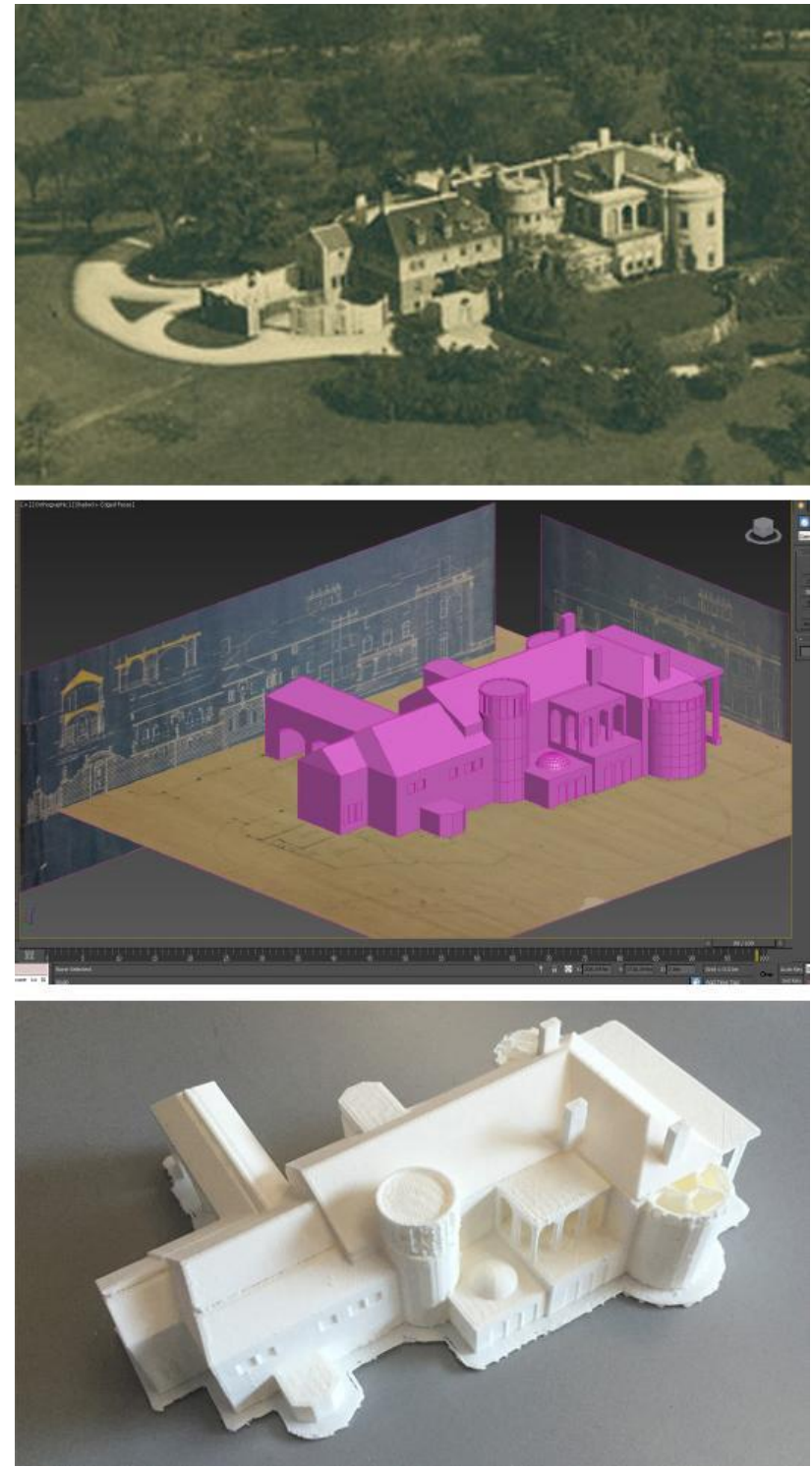

Figure 7. Process of 3D modeling Anderson mansion from referencing measured archival drawings and photograph. Carriage port visible at rear left of digital and fabricated models.

This exhaustive process, performed to meet the demands of the digital fabrication process, presents a new way of working which might incite deeper research and the discovery of new information. In the case of historic preservation research into traditional archival documentation for purposes of collection, it is common to find incomplete documentation. Although there is the need to continue searching in an effort to build the archive, it is understood and accepted that gaps in knowledge exist. These gaps may be allowed to persist until additional information resurfaces. In contrast, a comprehensive digitallyfabricated model can accommodate few if any gaps in knowledge in order to be an effective interpretive tool. It is not always possible to fill these gaps; information is often augmented through research into similar styles of a time period, similar works by a builder, and other typological information. Yet this is perhaps a last resort, as an original source will yield the most accurate and useful information to facilitate finalizing the model.

The digital fabrication of a model necessitates deep research to fill in missing areas of knowledge in the service of finalizing a physical representation. In attempting to reconcile the physical model in its entirety, this digital fabrication process can incentivize deeper research than might otherwise occur in the creation of a standalone archive. In this way, digital fabrication might itself begun to be understood as an emerging form of archival research.

\section{CONCLUSIONS}

These projects present a case study in digital applications to modern historic preservation documentation methods, providing a study of the Park's shift in significance away from its Gilded Age past and more towards public history and landscape preservation. As its program and physical composition have changed dramatically over time, Larz Anderson Park represents a specific type of rehabilitation project which is well suited for digital documentation and reconstruction techniques. Although the technologies used are not particularly novel on their own, their combination into the digital workflows discussed in this paper provide innovative methods in the application of archival research and heritage documentation that transition from recording for posterity to public engagement and education.

A key finding of this research surrounds the limitations of traditional archival research compared to digital fabrication. The research suggests that digital fabrication can serve as a valid form of archival research, serving as an interpretive tool which can bring specific types of information to light faster than the traditional documentation process. This is in part because of the nature of archival research: traditional archival research methods are based on fact finding and information gathering, making these methods limited in their interpretive value. Traditional archival research also has many limitations as a public education tool, as it takes a trained historian to piece together a historical narrative. Archival research is a necessary first step and provides the basis for digitally-fabricated models to exist, but is limited in the story it can tell to the public.

Digital fabrication, however, can translate historical accounts in a variety of formats - written or otherwise - into interactive representations. This format allows the public to visualize a part of history in ways that were never previously illustrated. An example of this is a sketch of the estate, presumably created by one of the main gardeners at Weld. This sketch, combined with the written accounts gathered of the estate, come to life in the digital fabrication process as a museum visitor can see first hand where the gardens were in relation to the main house, carriage house, and natural vegetation found on site (Figure 8). 

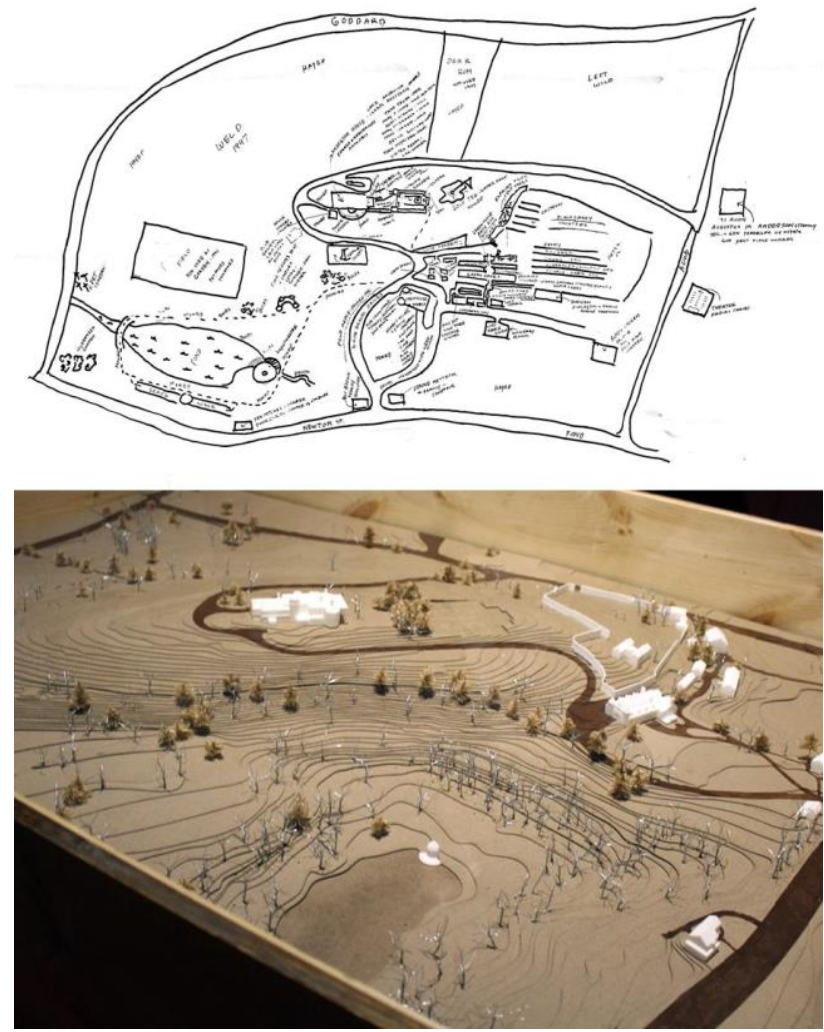

Figure 8 . Sketch of the original estate \& completed site model

This project was iterative, with multiple models being created throughout the research timeline, with each model embedding newer information as it was uncovered. Observing this process and the resulting artifacts which served as a sort of visual timeline of research, the researchers concluded that digitallyfabricated archival models are products which are inherently temporary in nature. This is not a product of material durability, but rather in the nature of archival research as nonfinite. Rather than being frozen moments in time, these digitally-fabricated models are representations of the most current information we have. Such visualizations are evolving and fluid, easily updated as digital 3D models and refabricated when new information becomes available through archival research.

This research indicates that the most successful applications of digital fabrication in archival research results when the model is understood as an iterative tool. Digital versioning - the naming of newer files by date or by number - serves a useful but unexpected purpose as it tracks information change over time, providing digital records of progress made by researchers (Figure 9).

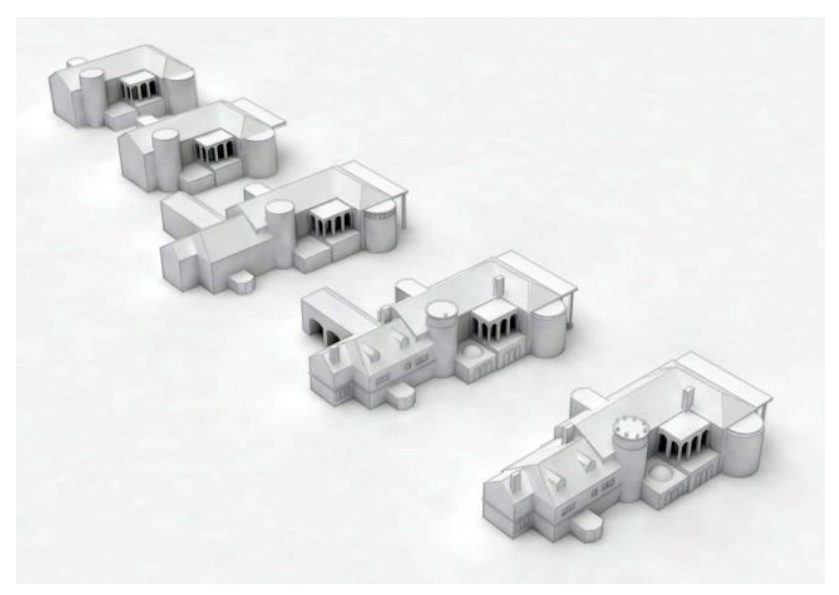

Figure 9. Iterative versions of the mansion reflecting changes in available information.

This conceptualization of the digital model reflects the archival document research process as visual artifact. A more traditional view of newer digital files might suggest that they represent the newest and most refined information. In turn, older files are usually seen as backups with limited utility. Conclusions drawn from the Larz Anderson research project offer an alternate view of these older models as innately worthwhile. As representations of various states of emerging knowledge, these models can serve as a visual timeline of the emergence of new information. This repositions the digital model versioning process not just as a set of files which become increasingly more accurate, but as a series of files which demarcate significant developments in the archival research process. Applications of this new sensibility towards the artifacts of 3D modeled archival research bear further exploration as a tool in their own right.

\section{REFERENCES}

Collins, Holly. 2006. "The Preservation Society of Newport County 1945-1965: The Founding Years," Research Fellow, September 82006.

Hii Jun Chung, Daniel; Zhou Zhiying, Steven; Karlekar, Jayashree; Schneider, Miriam and Lu, Weiquan. 2009. "Outdoor Mobile Augmented Reality for Past and Future OnSite Architectural Visualizations." T. Tidafi and T. Dorta (eds) Joining Languages, Cultures and Visions: CAADFutures 2009, PUM, 2009, pp. 557- 571

Ide, Evan P. 2004. Images of America: Larz Anderson Park. Charleston: Arcadia Publishing.

Kenworthy, Richard G. 1991. "Bringing the World to Brookline: The Gardens of Larz and Isabel Anderson.” Journal of Garden History vol. 11, no. 4 (1991) 224-241.

Lee, E., Paterson, I. and Maver, T. 2000. "Visualisation of Historic Village of New Lanark." SIGraDi'2000 - Construindo (n)o espacio digital (constructing the digital Space) (4th SIGRADI Conference Proceedings) Rio de Janeiro (Brazil) 2528 september 2000, pp. 177-178.

Martens, Bob; Martijn Stellingwerff. 2005. "Creating Physical Models Using Virtual Reconstructions: Mixed CAMTechniques for a Viennese Synagogue Scale-Model.” SIGraDi 
2005 - (Proceedings of the 9th Iberoamerican Congress of Digital Graphics) Lima - Peru 21-24 November 2005, vol. 1, pp. 108-113

Moskey, Stephen. 2016. Larz and Isabel Anderson: Wealth and Celebrity in the Gilded Age. Indiana: iUniverse.

Messenger, Phyllis and George Smith, eds. 2010. Cultural Heritage Management: A Global Perspective. Gainsville: University Press of Florida.

Oswald, Ansgar. 2008. Architectural Models. Barcelona: LINKS International.

Brookline Historical Society Newsletter. Spring, 1989.

Platt, Rutherford H., Rowan A. Rowntree and Pamela C. Muick, eds. 1994. The Ecological City: Preserving and Restoring Urban Biodiversity. Amherst: The University of Massachusetts Press.

Schmidt, Stephan J.2008. "The Evolving Relationship Between open Space Preservation and Local Planning Practice.” Journal of Planning History vol. 7, no. 2 (2008): 91-112. 